\title{
Patient education preferences in ophthalmic care
}

This article was published in the following Dove Press journal:

Patient Preference and Adherence

25 April 2014

Number of times this article has been viewed

\section{Jullia A Rosdahl \\ Lakshmi Swamy \\ Sandra Stinnett \\ Kelly W Muir}

Department of Ophthalmology, Duke Eye Center, Duke University, Durham, NC, USA
Correspondence: Jullia A Rosdahl

Department of Ophthalmology,

Duke Eye Center, Duke University,

235I Erwin Road, DUMC 3802, Durham, NC 277। 0 , USA

Tel + I 9196848850

$\mathrm{Fax}+\mid 9196818267$

Email jullia.rosdahl@duke.edu
Background: The learning preferences of ophthalmology patients were examined.

Methods: Results from a voluntary survey of ophthalmology patients were analyzed for education preferences and for correlation with race, age, and ophthalmic topic.

Results: To learn about eye disease, patients preferred one-on-one sessions with providers as well as printed materials and websites recommended by providers. Patients currently learning from the provider were older (average age 59 years), and patients learning from the Internet (average age 49 years) and family and friends (average age 51 years) were younger. Patients interested in cataracts, glaucoma, macular degeneration, and dry eye were older; patients interested in double vision and glasses were younger. There were racial differences regarding topic preferences, with Black patients most interested in glaucoma (46\%), diabetic retinopathy $(31 \%)$, and cataracts $(28 \%)$ and White patients most interested in cataracts $(22 \%)$, glaucoma (22\%), and macular degeneration (19\%).

Conclusion: Most ophthalmology patients preferred personalized education: one-on-one with their provider or a health educator and materials (printed and electronic) recommended by their provider. Age-related topics were more popular with older patients, and diseases with racial risk factors were more popular with high risk racial groups.

Keywords: patient education, eye disease, cataracts, macular degeneration, glaucoma, diabetic retinopathy

\section{Introduction}

Patient-centered care, one of the six domains identified by the Institute of Medicine, includes an informed patient who is an integral member of the care team. ${ }^{1,2}$ Educating patients about their diagnosis and plan of care is essential in all fields of medicine, including ophthalmology, where lack of patient engagement could result in irreversible blindness. The most common blinding diseases in the United States are macular degeneration, glaucoma, and diabetic eye disease. ${ }^{3}$ Cataracts are also common but can be cured with surgery.

A Cochrane Review of adherence for glaucoma medications ${ }^{4}$ concluded that education combined with behavioral interventions may improve adherence. Studies that solicited input from patients identified the importance of education in the care of glaucoma and diabetic retinopathy ${ }^{5,6}$ as well as partnership with patients. ${ }^{7}$ Not all patient education interventions are useful and effective for individual patients, particularly with respect to health literacy. ${ }^{8}$

Patient-centered education involves the patient as an adult learner. Principles of adult learning include framing new information on the foundation of the patient's life experiences and prior knowledge and accommodating diverse learning styles. ${ }^{9}$ To develop effective patient education interventions and materials and maximally involve the patients in the learning process, we need to understand their learning preferences, 
specifically in the ophthalmology population of older, possibly visually impaired, adults.

This study examines survey results from ophthalmology patients at a tertiary eye care center. The goal is to better understand the education preferences with respect to learning practices and topics of interest in this population and to guide the development of patient-centered educational interventions and materials targeted to older adults with eye diseases.

\section{Materials and methods}

A voluntary two-page survey (Figure S1) was distributed to patients at a tertiary eye care center and satellite clinics during 1 month (May 2012) as part of a quality improvement project to offer patient education lectures to the community on ophthalmology topics. Duke University Institutional Review Board permission was granted to analyze the deidentified survey results. The age and racial demographics of the eye center patient population were obtained by querying the Duke University Health System ${ }^{10}$ for comparison with the survey respondents.

The first page included questions about interest in patient education lectures, preferred times and locations, and preferred ophthalmic topics: cataracts, macular degeneration, glaucoma, diabetic eye disease, dry eye, double vision and lazy eye, glasses and contact lenses, low vision rehabilitation, laser vision corrective surgery, droopy eyelids and other cosmetic procedures of the face, and a section to write in other topics. The second page consisted of three questions about learning preferences and a space to write in race and age. The questions were, "What are some of the ways you currently learn about eye health and disease?" "Which of the following would help you to learn about eye health and disease?" "Where do you prefer to learn about eye health and disease?"

Statistical analyses were performed using SAS software, version 9.2 (SAS Inc., Cary, NC, USA). Descriptive statistics were summarized with percentages for groups and using means with percentages for ages. A Student's $t$-test was used to assess the significance of differences between means. A Fisher's exact test was used to assess the significance of differences among proportions. A $P$-value $<0.05$ was considered statistically significant.

\section{Results}

A total of 7,715 patients were seen during the month of survey distribution; 611 surveys ( $8 \%$ ) were completed, and 450 respondents indicated their race. There was no significant difference between the sample population and the total population of the patients seen at the eye center with regard to race (Figure 1). The respondents were younger (average age of 55 years) compared to the total patient population (average age of 59 years, $P<0.05$ ).

\section{Preferred learning practices}

Fifty-five percent of respondents overall preferred one-on-one sessions with eye care providers for learning about eye disease (Figure 2). Websites (38\% of respondents) and printed materials $(36 \%)$ recommended by the provider were preferred; $29 \%$ of respondents like one-on-one sessions with an eye health educator. Respondents noted interest in videos of lectures (14\%), web-based modules (12\%), in-person lectures $(12 \%)$, group sessions with providers $(12 \%)$, self-selected websites (11\%), self-selected printed materials $(11 \%)$, and group sessions with eye health educators $(10 \%)$.

One-on-one sessions were favored by older patients (average age of 56 years for those who preferred one-on-one sessions with eye care provider compared with average age 53 for those who did not, $P=0.047$ ) (Table 1). Web-based learning modules were favored by younger patients (average age 48 years for those who preferred web-based learning

All patients seen at eye center May 2012

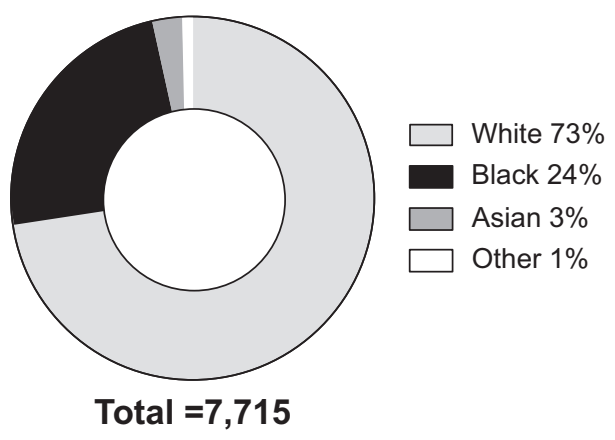

Survey respondents with race data

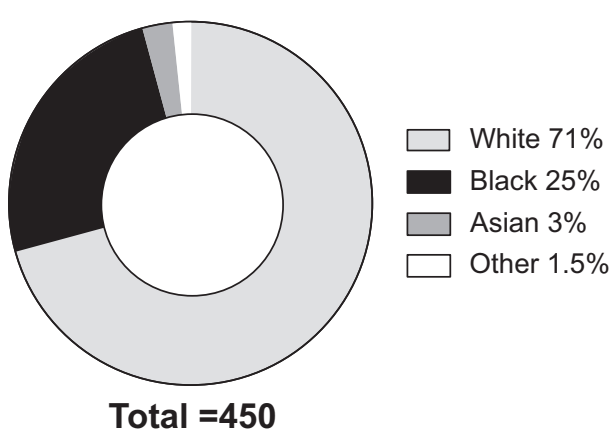

Figure I Racial distribution of the eye center population and the survey respondents.

Notes: During the month of survey distribution (May 20I2), 7,7I5 patients were seen at the eye center. The upper graph represents the racial distribution of the total eye center population seen during May 2012. Most were White (73\%) or Black (24\%). The lower graph represents the racial distribution of the survey respondents who indicated a race on their survey. Of the 611 surveys completed for the quality improvement project, 450 respondents wrote in their race, with $71 \%$ White and $25 \%$ Black. The racial distribution is very similar between the two groups; $P<0.000$ I using the chi-squared test. 


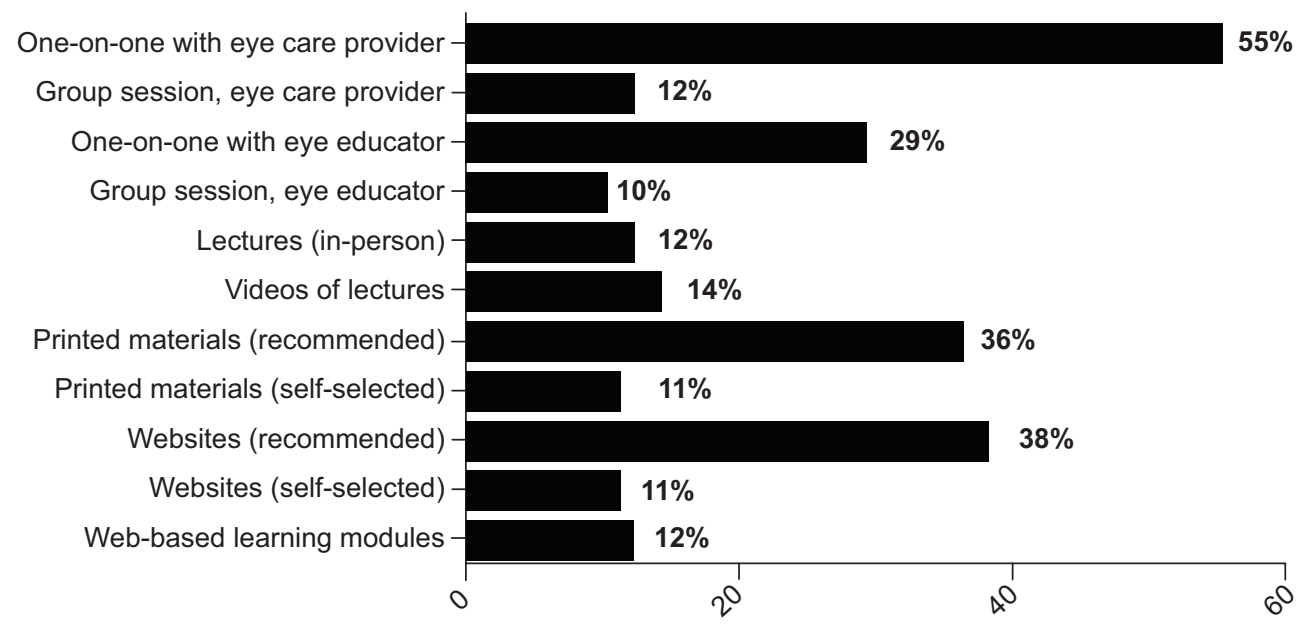

Percent of respondents

Figure 2 Preferred learning practices.

Notes: The survey question asked "Which of the following would help you to learn about eye health and disease? Check all that apply." The bars represent the percentage of respondents who selected each answer. Overall, one-on-one sessions with providers were preferred. One-on-one sessions with eye health educators and resources recommended by the provider (both printed and websites) were preferred. There was interest in all practices listed.

modules compared with average age 56 years for those who did not, $P=0.001$ ).

Different learning practices were associated with ophthalmic topics of interest and are summarized in Table 2. Of note, self-selected websites were not associated with any individual ophthalmic topic.

\section{Age and racial demographics of patients interested in ophthalmic topics}

Patients with interest in cataracts (average age 61 years), macular degeneration (average age 63 years), glaucoma (average age 59 years), and dry eye (average age 60 years) were older than patients who were not interested in those topics (average age 54 years) (Table 3 ). An interest in double vision (average age 46 years) and glasses and contact lenses (average age 50 years) was associated with younger age.

Black patients were more likely to be interested in glaucoma (46\% of Black respondents) and diabetic eye disease (31\%) compared with other races (Table 4). White patients were more likely to be interested in macular degeneration (19\% of White respondents, compared with $9 \%$ of Black respondents). A higher proportion of Black patients

Table I Preferred learning practice with age and race

\begin{tabular}{|c|c|c|c|c|c|c|c|}
\hline & \multirow[t]{2}{*}{$\begin{array}{l}\text { Age mean, } \\
\text { years (SD) }\end{array}$} & \multicolumn{5}{|c|}{$\begin{array}{l}\text { Race } \\
\text { Number of survey respondents (\%, within race category) }\end{array}$} & \multirow[t]{2}{*}{$P$-value* } \\
\hline & & White & Black & Hispanic & Asian & Other & \\
\hline $\begin{array}{l}\text { One-on-one session } \\
\text { with eye care provider }\end{array}$ & $56(19)$ & $209(68 \%)$ & $82(73 \%)$ & $6(60 \%)$ & $6(50 \%)$ & $33(20 \%)$ & $<0.001$ \\
\hline $\begin{array}{l}\text { Group session } \\
\text { with eye care provider }\end{array}$ & $57(14)$ & $43(14 \%)$ & $22(20 \%)$ & 0 & I (8\%) & $8(5 \%)$ & $0.00 \mathrm{I}$ \\
\hline $\begin{array}{l}\text { One-on-one session } \\
\text { with eye health educator }\end{array}$ & $58(18)$ & 107 (35\%) & $46(41 \%)$ & $2(20 \%)$ & $4(33 \%)$ & $21(13 \%)$ & $<0.001$ \\
\hline $\begin{array}{l}\text { Group session } \\
\text { with eye health educator }\end{array}$ & $58(15)$ & $39(13 \%)$ & $16(14 \%)$ & 0 & $2(17 \%)$ & $4(2 \%)$ & $<0.001$ \\
\hline Lectures & $58(17)$ & $43(14 \%)$ & $21(19 \%)$ & I (I0\%) & I (8\%) & $6(4 \%)$ & $<0.001$ \\
\hline $\begin{array}{l}\text { Printed materials } \\
\text { chosen by provider }\end{array}$ & $57(18)$ & I 45 (47\%) & $56(50 \%)$ & I (10\%) & $3(25 \%)$ & $18(11 \%)$ & $<0.001$ \\
\hline $\begin{array}{l}\text { Printed materials, } \\
\text { patient's choice }\end{array}$ & $54(19)$ & $40(13 \%)$ & $15(13 \%)$ & $3(30 \%)$ & $2(17 \%)$ & $8(5 \%)$ & 0.006 \\
\hline Websites, patient's choice & $52(18)$ & $46(15 \%)$ & $12(11 \%)$ & $2(20 \%)$ & I (8\%) & 7 (4\%) & 0.003 \\
\hline Web-based learning modules & $48(18)$ & $43(14 \%)$ & $15(13 \%)$ & $2(20 \%)$ & $3(25 \%)$ & $9(5 \%)$ & 0.011 \\
\hline
\end{tabular}

Notes: The age and racial composition of the survey respondents who noted what learning practices would help to learn about eye diseases are summarized. The survey question was "Which of the following would help you to learn about eye health and disease? Check all that apply." The age listed is the average age of the respondents who selected the learning practice. The racial distribution is shown, with the percentage within each racial category; $* P$-value based on Fisher's exact test of differences among proportions of race.

Abbreviation: SD, standard deviation. 
Table 2 Ophthalmic topics and preferred learning practice

\section{Ophthalmic topic}

Cataracts

Macular degeneration

Glaucoma

Diabetic retinopathy

Dry eye

Double vision

Glasses and contact lenses

Low vision rehabilitation

Laser vision corrective surgery

Eyelid surgery and cosmetic procedures of the face

\section{Preferred learning practice ( $P$-value*)}

Comparison of those with and without interest in the ophthalmic topic

Group session with eye care provider $(<0.00 \mathrm{I})$

One-on-one session with eye health educator $(<0.001)$

Group session with eye health educator $(<0.00 \mathrm{I})$

Lectures (in-person) $(<0.00 \mathrm{I})$

Videos of lectures $(0.007)$

Printed materials chosen by provider $(0.016)$

Group session with eye care provider $(<0.001)$

Group session with eye health educator $(<0.00 \mathrm{I})$

Lectures (in-person) $(<0.00 \mathrm{I})$

Videos of lectures $(0.001)$

One-on-one session with eye care provider $(<0.001)$

Group session with eye care provider $(<0.00 \mathrm{I})$

One-on-one session with eye health educator $(<0.00 \mathrm{I})$

Group session with eye health educator $(0.00 \mathrm{I})$

Lectures (in-person) $(<0.00 \mathrm{I})$

Videos of lectures $(<0.00 \mathrm{I})$

Printed materials chosen by provider $(<0.00 \mathrm{I})$

Printed materials, patient's choice $(0.043)$

Websites, recommended by provider $(<0.00 \mathrm{I})$

Group session with eye care provider $(0.010)$

One-on-one session with eye health educator (0.009)

Group session with eye health educator $(0.03 \mathrm{I})$

Lectures (in-person) (0.029)

Group session with eye care provider $(0.02 \mathrm{I})$

One-on-one session with eye health educator $(<0.00 \mathrm{I})$

Group session with eye health educator $(<0.00 \mathrm{I})$

Lectures (in-person) $(<0.001)$

Videos of lectures $(0.04 \mathrm{I})$

Printed materials chosen by provider $(0.010)$

Printed materials, patient's choice (0.009)

Group session with eye care provider (0.04I)

Group session with eye health educator (0.046)

Videos of lectures (0.049)

Web-based learning modules (0.037)

One-on-one session with eye health educator (0.047)

Group session with eye health educator $(<0.00 \mathrm{I})$

Lectures (in-person) $(<0.00 \mathrm{I})$

Printed materials chosen by provider $(<0.00 \mathrm{I})$

Printed materials, patient's choice $(<0.00 \mathrm{I})$

Websites, recommended by provider $(0.002)$

Web-based learning modules $(0.001)$

Group session with eye care provider $(<0.00 \mathrm{I})$

One-on-one session with eye health educator $(0.003)$

Group session with eye health educator $(0.007)$

Lectures (in-person) (0.006)

Videos of lectures $(<0.00 \mathrm{I})$

Printed materials, patient's choice (0.019)

One-on-one session with eye care provider $(0.014)$

Lectures (in-person) (0.050)

Printed materials, patient's choice $(0.0 \mathrm{II})$

Notes: The associated learning practices for each ophthalmic topic are summarized. For example, for cataracts, the respondents who noted an interest in cataracts were compared to those who did not select cataracts. The respondents who were interested in cataracts were more likely to select group session with eye care provider, one-on-one session with eye health educator, group session with eye health educator, in-person lectures, videos of lectures, and printed materials chosen by provider. The differences for each of these learning practices between those interested in cataracts and those who were not were statistically significant with the $P$-value $<0.05$. Only statistically significant associations are listed in the table; ${ }^{*} P$-value based on Fisher's exact test of difference in proportions. 
Table 3 Ophthalmic topics of interest and age

\begin{tabular}{llll}
\hline & $\begin{array}{l}\text { Age } \\
\text { Mean, years (SD) }\end{array}$ & \multicolumn{1}{c}{$P$-value* } \\
\cline { 2 - 3 } & Yes, interested & No, not interested & $<0.001$ \\
\hline Cataracts & $61(16)$ & $54(19)$ & $<0.001$ \\
Macular degeneration & $63(14)$ & $54(19)$ & 0.014 \\
Glaucoma & $59(16)$ & $54(20)$ & 0.231 \\
Diabetic retinopathy & $58(15)$ & $55(19)$ & 0.006 \\
Dry eye & $60(17)$ & $56(19)$ & 0.003 \\
Double vision & $46(18)$ & $57(19)$ & 0.002 \\
Glasses and contact lenses & $50(18)$ & $55(19)$ & 0.553 \\
Low vision & $57(19)$ & $56(19)$ & 0.163 \\
Laser vision correction & $52(20)$ & $55(19)$ & 0.221 \\
Droopy eyelids & $59(18)$ & & \\
\hline
\end{tabular}

Notes: The average age of the respondents who noted an interest in each of the ophthalmic topics are listed. For example: for cataracts, the average age of the respondents who selected "cataracts" as a topic of interest was $6 \mathrm{I}$ years old; the average age of those who did not select "cataracts" was 54 years old.

*P-value based on $t$-test of difference between categories for means of age.

Abbreviation: SD, standard deviation.

were more likely to be interested in low vision and glasses compared to Whites.

\section{Current learning practices}

Patients who responded that they learn about eye disease from an eye care professional were older (average age 58, compared to 51 for those not learning from an eye care professional, $P<0.001$ ) (Table 5). Patients who responded that they use the Internet to learn about eye disease were younger (average age 49, compared to 59 for those not using the Internet, $P<0.001)$. Survey respondents who learn from family and friends were younger (average age 51 compared to 56 for those not learning from family and friends, $P=0.012$ ).

There were racial differences in responses. The majority of White patients (66\%) and majority of Black patients (64\%) noted that they were currently learning about eye disease from an eye care professional. The numbers of Hispanic and Asian respondents were much lower (ten and eleven respondents, respectively), consistent with the local population.

\section{Preferred learning location}

Most patients preferred to learn about eye disease either at home or the eye center (Figure 3). Overall, however, one in five preferred the primary care provider, particularly for learning about low vision rehabilitation and laser vision corrective surgery.

\section{Discussion}

This study adds to our understanding of educational preferences with respect to learning practices and topics of interest for ophthalmology patients at a tertiary care center.

Table 4 Ophthalmic topics of interest and race

\begin{tabular}{|c|c|c|c|c|c|c|}
\hline & & & & & & \multirow[t]{4}{*}{$P$-value* } \\
\hline & \multicolumn{5}{|c|}{ Number of survey respondents $(\%$, within race category) } & \\
\hline & White & Black & Hispanic & Asian & Other & \\
\hline & 309 & 112 & 10 & II & 169 & \\
\hline Cataracts & $67(22 \%)$ & $31(28 \%)$ & 0 & $5(42 \%)$ & $35(21 \%)$ & 0.110 \\
\hline Macular degeneration & 59 (19\%) & $10(9 \%)$ & I (I0\%) & $4(33 \%)$ & $28(17 \%)$ & 0.048 \\
\hline Glaucoma & $67(22 \%)$ & $5 \mathrm{I}(46 \%)$ & 0 & $4(33 \%)$ & $45(27 \%)$ & $<0.001$ \\
\hline Diabetic retinopathy & $23(7 \%)$ & $35(31 \%)$ & I (I0\%) & $2(17 \%)$ & $22(13 \%)$ & $<0.001$ \\
\hline Dry eye & $50(16 \%)$ & 20 (I8\%) & $2(20 \%)$ & $3(25 \%)$ & $29(17 \%)$ & 0.852 \\
\hline Double vision & $18(6 \%)$ & $12(11 \%)$ & 0 & 0 & $9(5 \%)$ & 0.380 \\
\hline Glasses and contact lenses & $51(17 \%)$ & $30(27 \%)$ & $2(20 \%)$ & $3(25 \%)$ & $20(12 \%)$ & 0.022 \\
\hline Low vision & $24(8 \%)$ & $22(20 \%)$ & I (10\%) & 0 & $16(10 \%)$ & 0.012 \\
\hline Laser vision correction & $28(9 \%)$ & $18(16 \%)$ & 0 & $2(17 \%)$ & $13(8 \%)$ & 0.120 \\
\hline Droopy eyelids & $23(7 \%)$ & $9(8 \%)$ & 0 & $\mathrm{I}(8 \%)$ & $12(7 \%)$ & 0.988 \\
\hline
\end{tabular}

Notes: The racial composition of the respondents who noted an interest in each of the ophthalmic topics are listed. For example: for cataracts, of the respondents who indicated white race, $22 \%$ selected "cataracts"; of those who indicated black race, $28 \%$ selected "cataracts"; none of the Hispanic respondents selected "cataracts"; of the Asian respondents, $42 \%$ selected "cataracts"; and of the respondents who did not indicate a race, $21 \%$ selected "cataracts". *P-value based on Fisher's exact test of differences among proportions. 
Table 5 Current route of eye health information: age and racial characterization

\begin{tabular}{|c|c|c|c|c|c|c|c|}
\hline & $\begin{array}{l}\text { Primary } \\
\text { medical doctor }\end{array}$ & $\begin{array}{l}\text { Eye care } \\
\text { professional }\end{array}$ & $\begin{array}{l}\text { Duke } \\
\text { ophthalmologist } \\
\text { optometrist }\end{array}$ & Internet & $\begin{array}{l}\text { Printed } \\
\text { educational } \\
\text { materials }\end{array}$ & Television & $\begin{array}{l}\text { Friends/ } \\
\text { family }\end{array}$ \\
\hline \multicolumn{8}{|c|}{ Age of those who responded } \\
\hline \multicolumn{8}{|c|}{ Mean, years (SD) } \\
\hline Yes & $54(18)$ & $58(17)$ & $59(18)$ & $49(17)$ & $57(17)$ & $54(18)$ & $5 I(20)$ \\
\hline No & $56(20)$ & $5 I(2 I)$ & $53(19)$ & $59(19)$ & $55(20)$ & $56(19)$ & $56(18)$ \\
\hline$P$-value* & 0.130 & $<0.001$ & $<0.001$ & $<0.001$ & 0.245 & 0.529 & 0.012 \\
\hline \multicolumn{8}{|l|}{ Race } \\
\hline \multicolumn{8}{|c|}{ Number of survey respondents (\%, within race category) } \\
\hline $\begin{array}{r}\text { White } \\
309\end{array}$ & $110(36 \%)$ & $205(66 \%)$ & I 44 (47\%) & 131 (42\%) & $72(23 \%)$ & $38(12 \%)$ & $68(22 \%)$ \\
\hline $\begin{array}{l}\text { Black } \\
1 / 2\end{array}$ & $41(37 \%)$ & $72(64 \%)$ & 47 (42\%) & $4 \mathrm{l}(37 \%)$ & 29 (26\%) & $28(25 \%)$ & $34(30 \%)$ \\
\hline $\begin{array}{c}\text { Hispanic } \\
10\end{array}$ & I (I0\%) & $2(20 \%)$ & $3(30 \%)$ & $4(40 \%)$ & I (10\%) & $3(30 \%)$ & $3(30 \%)$ \\
\hline $\begin{array}{c}\text { Asian } \\
\text { II }\end{array}$ & $5(42 \%)$ & $6(50 \%)$ & $3(25 \%)$ & $4(33 \%)$ & $3(25 \%)$ & $0(0 \%)$ & 4 (33\%) \\
\hline $\begin{array}{r}\text { Other } \\
169\end{array}$ & 27 (16\%) & 35 (2।\%) & $16(10 \%)$ & I8 (II\%) & $10(6 \%)$ & $12(7 \%)$ & 12 (7\%) \\
\hline$P$-value** & $<0.001$ & $<0.001$ & $<0.00 \mathrm{I}$ & $<0.001$ & $<0.001$ & $<0.001$ & $<0.001$ \\
\hline
\end{tabular}

Notes: The age and racial composition of the survey respondents who noted how they are currently learning about eye diseases are summarized. The survey question was "What are some of the ways you currently learn about eye health and disease? Check all that apply." For example, for primary medical doctor, the average age of the respondents who noted that they are currently learning about eye diseases from their primary medical doctor was 54 years old; the average age of those who did not select "primary medical doctor" was 56 years old. Of the respondents who indicated White race, $36 \%$ selected "primary medical doctor" in answer to this question; of the Black respondents, 37\% selected "primary medical doctor"; of the Hispanic respondents, one or 10\% selected "primary medical doctor"; of the Asian respondents, 42\% selected "primary medical doctor"; and of the respondents who did not indicate a race, $16 \%$ selected "primary medical doctor"; $* P$-value based on Student's $t$-test of difference between categories for means of age; **P-value based on Fisher's exact test of difference among proportions.

Abbreviation: SD, standard deviation.

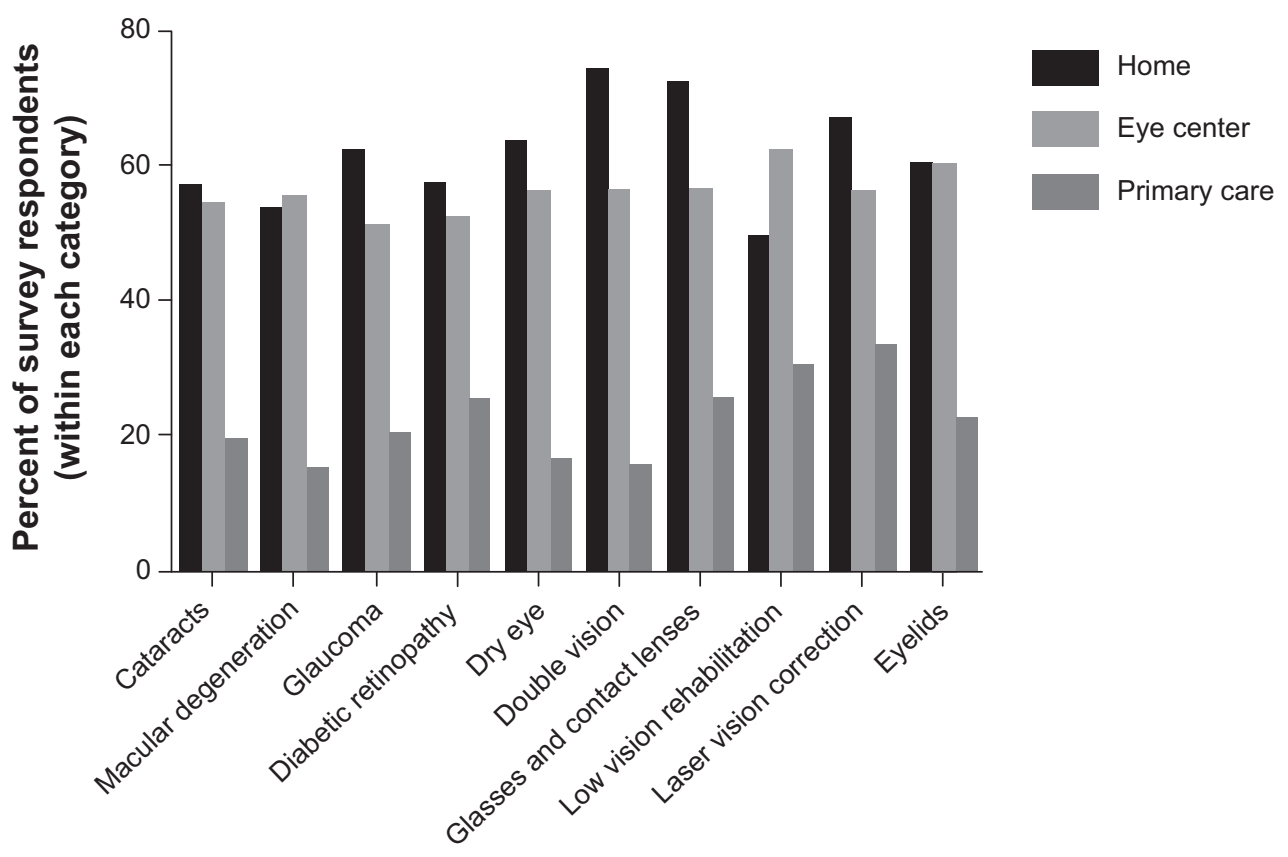

Figure 3 Preferred locations for learning about ophthalmic topics.

Notes: The survey question asked "Where do you prefer to learn about eye health and disease? Check all that apply." Of the subtotal of respondents who noted a preference for the specific topic, the bars represent the percentage of respondents who preferred each location (home/eye center/primary care). For example, for cataracts, $57 \%$ of the respondents who noted an interest in cataracts also noted a preference for learning at home, $54 \%$ of those respondents noted a preference for the eye center, and $19 \%$ noted a preference for the primary care location. The total percentage is greater than 100 because respondents could choose more than one. Overall, survey respondents preferred learning about ophthalmology topics at home and at the eye center. However, about $20 \%$ of respondents noted a preference for learning about ophthalmology topics at the primary care doctor's office, particularly concerning the topics of low vision and laser vision correction, with one in three respondents noting the preference for primary care. 
The survey was voluntary and no compensation was offered; $8 \%$ of patients filled out the survey. The demographic comparison with the total patient population suggests that the survey respondents are representative of the ophthalmology patient population with regard to race and age (average age in the sixth decade).

The survey, designed for a quality improvement project, is not a validated research tool. The demographic answers were not verified, nor was it possible to verify whether a diagnosis of interest recorded on the survey corresponded to a patient's diagnosis. Another limitation of this retrospective study is that patients could select more than one answer for each question; a survey allowing only one answer or a ranking of multiple answers would allow for a more accurate indication of patient preferences. The survey was only offered in English, thus excluding non-English-speaking patients. Patients unable to read due to low vision or low literacy were unlikely to fill out the survey, although accommodations were made for low vision (yellow paper, large font). The education level of the patients was not assessed, limiting the generalizability of the results. The patient population was a tertiary eye care population at a single institution, thus the results may not apply to populations at other types of practices. Also, the low numbers of non-White, non-Black patients were consistent with the local population but suggest that the results may not reflect the preferences of all races.

In this study, we found an association between interest in cataracts and preferred learning practices of eye provider and educator teaching sessions, lectures, videos, and printed materials. This correlation is supported by a study in a Veterans Affairs Health System population of cataract surgery patients. Shukla et $\mathrm{al}^{11}$ found that interventions that included conventional verbal information plus either printed materials at eighth-grade reading levels or a videotape presentation optimized patient understanding of cataract surgery risks/benefits/alternatives. Conversely, we found an association with a preference for lectures and the topics of diabetic retinopathy and cataracts, two common indications for dilated eye exams in older adults. When Owsley et $\mathrm{a}^{12}$ examined the effect of health education sessions on the importance of dilated eye exams for older African American participants, they found no change in dilated eye exam rates before and after the education event. However, they did not assess participant comprehension and learning.

In conclusion, most ophthalmology patients surveyed preferred personalized education interventions, such as one-on-one education sessions, and materials (printed and electronic) recommended by their provider. Age-related topics were more popular with older patients, and diseases with racial risk factors were more popular with high risk racial groups. An enhanced understanding of education preferences could help to develop more effective education interventions and materials for this population of adult learners with eye disease.

With regards to implications for practice, patients with eye disease value printed materials and websites recommended for them by their providers. Primary care locations may consider offering information about low vision rehabilitation and laser vision corrective surgery, as these topics were preferred at primary care locations.

\section{Disclosure}

JAR receives salary support from a K12 career development award from the National Eye Institute. KWM receives salary support from a VA HSR \& D career development award. The authors report no other conflicts of interest in this work.

\section{References}

1. Crossing the Quality Chasm: A New Health System for the 21 st Century, Institute of Medicine, March 2001. National Academy Press. Available from: http://www.nap.edu/books/0309072808/html. Accessed April 10, 2014.

2. Hahn SR. Patient-centered communication to assess and enhance patient adherence to glaucoma medication. Ophthalmology. 2009;116(11 Suppl):S37-S42.

3. Vision Problems in the US: Prevalence of Adult Vision Impairment and Age-related Eye Disease in America. Prevent Blindness America 2002. Available from: http://www.usvisionproblems.org. Accessed January 7, 2014.

4. Waterman H, Evans JR, Gray TA, Henson D, Harper R. Interventions for improving adherence to ocular hypotensive therapy. Cochrane Database Syst Rev. 2013;4:CD006132.

5. Yan X, Liu T, Gruber L, He M, Congdon N. Attitudes of physicians, patients, and village health workers toward glaucoma and diabetic retinopathy in rural China: a focus group study. Arch Ophthalmol. 2012; 130(6):761-770

6. Abueleinen KG, El-Mekawey H, Saif YS, Khafagy A, Rizk HI, Eltahlawy EM. Sociodemographic factors responsible for blindness in diabetic Egyptian patients. Clin Ophthalmol. 2011;5:1593-1598.

7. Koutroumanos N, Folkard A, Mattocks R, et al. Bringing together patient and specialists: the first Birdshot Day. Br J Ophthalmol. 2013;97(5):648-652.

8. Muir KW, Lee PP. Health literacy and ophthalmic patient education. Surv Ophthalmol. 2010;55(5):454-459.

9. Collins J. Education techniques for lifelong learning: principles of adult learning. Radiographics. 2004;24(5):1483-1489.

10. Horvath MM, Winfield S, Evans S, Slopek S, Shang H, Ferranti J. The DEDUCE Guided Query tool: providing simplified access to clinical data for research and quality improvement. J Biomed Inform. 2011;44(2):266-276.

11. Shukla AN, Daly MK, Legutko P. Informed consent for cataract surgery: patient understanding of verbal, written, and videotaped information. $J$ Cataract Refract Surg. 2012;38(1):80-84.

12. Owsley C, McGwin G, Searcey K, et al. Effect of an eye health education program on older African Americans' eye care utilization and attitudes about eye care. J Natl Med Assoc. 2013;105(1):69-76. 


\section{Supplementary material}

\section{(14) Duke eye center}

\section{Patient Survey
Page 1 of 2}

Are you interested in coming to lectures given by Duke eye center physicians about common eye problems and diseases and how to keep your eyes healthy?
$\square$ Yes
$\square$ No

What time of day would be best for you? Please check all that apply.

$\square$ During the morning, for example $10 \mathrm{AM}$, on a weekday

$\square$ During the afternoon, for example 2 PM, on a weekday

$\square$ At noon, such that you bring your lunch and attend during your lunch hour

$\square$ In the evening, for example 6 PM, on a weekday

$\square$ During the day on a weekend

What location is best for you? Please check all that apply.

At the Main Eye Center; 2351 Erwin Rd, Durham

Or at one of the Eye Center satellites:

$\square$ Page Road; 4709 Creekstone Dr, Durham

$\square$ Cary; 2000 Regency Pkwy, Cary

$\square$ North Durham; 3116 N. Duke St, Durham

$\square$ Raleigh; 3480 Wake Forest Rd, Raleigh

$\square$ Southpoint; 6301 Herndon Rd, Durham

Winston-Salem; 2025 Frontis Plaza Blvd, Winston-Salem

\section{What topics interest you? Please check all that apply.}

$\square$ Cataracts

$\square$ Macular degeneration

$\square$ Glaucoma

Diabetic eye disease

$\square$ Dry eye

$\square$ Double vision and lazy eye

$\square$ Glasses and contact lenses

$\square$ Low vision rehabilitation

$\square \quad$ Laser vision corrective surgery (for example, LASIK surgery)

$\square$ Droopy eyelids and other cosmetic procedures of the face

Other topics (please list):

OPTIONAL: If you would like to be contacted with details about the upcoming Course on Keeping Your Eyes Healthy, please provide us with your name and contact information.

Name:

How would you like us to contact you?

Telephone:

E-mail:

Mailing address: 


\section{Health education for our patients}

At the Duke eye center, we want to provide you with the best ophthalmic care possible, and that includes helping to educate you about your eyes. The purpose of this survey is to identify ways you would like to get information about healthy eyes and eye diseases. Our goal is to provide you with the best information in the format most helpful to you.

What are some of the ways you currently learn about eye health and disease? Check all that apply.

$\square$ Primary medical doctor (PCP, internist, etc.)

$\square$ Eye care professional

$\square$ Duke Ophthalmologist/optometrist

$\square$ Internet

$\square$ Printed educational materials

$\square$ Television

$\square$ Friends/family

Other (please describe):

Which of the following would help you to learn about eye health and disease? Check all that apply.

$\square$ One-on-one session with your eye care provider (for example, during scheduled office visits)

$\square$ Group session with your eye care provider and other patients with the same eye condition

$\square$ One-on-one session with a professional eye health educator (for example, a highly trained ophthalmic technician with experience taking care of patients like you)

$\square$ Group session with a professional eye health educator and other patients with the same eye condition

$\square$ Lectures (in-person) by Duke eye center experts, on eye health and disease

$\square$ Videos of lectures by Duke eye center experts

$\square$ Printed educational materials, chosen specifically for you by your eye care provider

$\square$ Printed educational materials, of your choosing

$\square$ Websites recommended by your eye care provider

$\square$ Websites of your own choosing

$\square$ Web-based learning modules, for example, videos of lectures with additional reading materials

Other (please describe):

Where do you prefer to learn about eye health and disease? Check all that apply.

$\square$ At home (with printed materials, computer, television)

$\square$ At work

$\square$ At the Duke eye center

$\square$ At my primary medical doctor's office

Other (please describe):

If English is not your preferred language, what other languages should be offered?

\section{What is your age?}

What is your race? 
Patient Preference and Adherence

Dovepress

\section{Publish your work in this journal}

Patient Preference and Adherence is an international, peer-reviewed, open access journal that focusing on the growing importance of patient preference and adherence throughout the therapeutic continuum. Patient satisfaction, acceptability, quality of life, compliance, persistence and their role in developing new therapeutic modalities and compounds to optimize

clinical outcomes for existing disease states are major areas of interest for the journal. This journal has been accepted for indexing on PubMed Central. The manuscript management system is completely online and includes a very quick and fair peer-review system, which is all easy to use. Visit http://www. dovepress.com/testimonials.php to read real quotes from published authors.

Submit your manuscript here: http://www.dovepress.com/patient-preference-and-adherence-journal 